\title{
Culture-building in action: developing a vision for Global Inc.
}

\author{
A. Whiteley \\ Graduate School of Business, Curtin University of Technology \\ Western Australia, Tel: +619351 7714, Fax: +619351 3368, \\ E-mail: A.Whiteley@info.curtin.edu.au
}

\begin{abstract}
This paper is written from an Organisational Behavior perspective. The paper reports on a set of activities that involved the collaboration of Organisational Behavior and Information Technology disciplines. The Organisational Behavior activities concerned culture building and the Information Technology concerned the use of Group Support Systems technology. The focus is using the values of key stakeholding groups in an organisation to build a strong and shared culture. The method being reported on is the core values model and method (Whiteley, 1995), although there seems no reason why other culture building methods would not work equally well. One of the objectives of the core values model is vision creation. The model and method were developed specifically for this purpose. They were developed over several years of workshops in Hong Kong and Australia, with ongoing critical feedback from manager, worker and customer groups. They have also been used for several years as part of MBA International Business teaching and have benefitted similarly in terms of critical feedback from a multicultural student group.
\end{abstract}

\section{Keywords}

GSS for Culture building, corporate culture, core values and GSS

\section{INTRODUCTION}

This paper describes the use of a well-trialled model or framework which helps groups create a shared vision in a Group Support Systems environment. Group Support Systems technology was first encountered by the author in a decision making environment. Although GSS is now acknowledged for its process as well as outcomes capabilities, it was tentatively adopted at first because of the emotional and imaginal requirements of vision-making in contrast to the mechanised properties of the GSS environment. 
In the culture building situation the "efficiencies" leverage of GSS is not as important as the need to create a supportive and creative atmosphere. GSS is now being adopted with confidence for the sensitive and imaginative task of vision-making.

The paper will briefly describe the concept of corporate culture and its importance to managers, the anthropological notion of key organising principles, the epistemological basis of the core values model and a description of the method itself, as used practically, in organisations. GSS software incorporates properties that can help offset human frailties as they surface in meetings. These will be discussed. The paper will conclude by proposing a 'hands on' simulation of a vision making session at the 1996 IFIP conference.

\section{CORPORATE CULTURE}

\section{Culture}

The idea of culture is that it is an organising principle for the "we-ness" of a defined group of people bound together in a social setting. The deep generative moral, legal and social rules that prescribe acceptable behavior for the good of the group are implicit in the strategies structures and customs that are acceptable as 'normal', standards in daily life. As organised work is a feature of modern living it seems likely that this applies also to organisational life. Culture, unlike many of the other social systems that have to be flexible and malleable to survive change, evolves to form patterns of behavior that become embedded in the actions and reactions of group members. In other words whilst societies require many of their social systems to be flexible and responsive in the face of continuous change, cultural activities are directed towards becoming deeply held and valued anchors to hang on to in the face of turbulence and change.

From an organisational point of view, producing a strong culture could mean producing a stabilising factor in an otherwise seemingly unstable environment. The question is: Do organisations qualify as being 'cultures'? (The term culture is used in the 'definable group' sense rather than the sociological sense of sub-culture). If they do, can culture building serve the organisation as a key stability forming activity?

Adler (1993), drawing on the work of anthropologists, highlights some defining aspects of culture. Barnouw (1985) describes culture as "a way of life of a group of people...", Kroeber and Kluckholn (1952:181) write that "...the essential core of culture consists of traditional (i.e., historically derived and selected) ideas and especially their attached values. Following his seminal work in the 1980's, Hofstede (1984:21) talks about culture as it 'determines the identity of a human group in the same way that personality determines the identity of an individual.'. He treats culture as "the collective programming of the mind which distinguishes the members of one human group from another". Although most writers in the corporate culture field acknowledge that culture is not readily captured or transparent there seems to be a consensus that corporate culture exists as an important organisational entity. Writers such as Schein (1985:51), Pugh (1993), Frost, et al (1991) make a convincing case for the existence of organisational or corporate culture (notwithstanding unresolved dilemmas and competing perspectives).

\section{Key organising principles}

Apart from making the diagnostic contribution to studying culture, with the now famous cultural dimensions of Power Distance, Uncertainty Avoidance, Masculine/Feminine, Individual/Collective frameworks, Hofstede (1984) coined the term 'Business Anthropology' and expressed the thought that this would be important for organisations (Hofstede, 1989). This led the author to adopt an 
anthropological approach when thinking about culture in organisations and the idea of key organising principles. This entails thinking about people at work as they go about developing the aspects of life they particularly value as being essential to successful living.

Central to any culture is its key organising principles. These are the 'designs for living' that have been worked out, over time, in such a way as to become a blueprint in terms of moral, social, legal patterns or value rules of behavior. Whilst each society or social group has different rules about, for example, educating, socialising, doing what is right, they all have rules. These rules have to be worked out by the group members as they find ways to 'live' and work together that feel comfortable and successful. In the organisational setting, each organisation develops its own rules (stated or unstated) about training and development, socialisation and distribution of status, and basically what it is 'OK to do around here'.

This anthropological approach guided the task of developing a process framework by which any business or organisation anywhere in the world could construct a shared vision. There is a premise that although the sort of values held by group members are different in each country, or indeed in each business, that each group holds values is a common factor. When presenting the core values process model to a multicultural group of people there is a high degree of agreement on its applicability in different cultural settings, although the method would vary according to things like the authority structures and systems in place.

\section{Values, key constructs in understanding culture.}

Put informally, each of us carries within ourselves the essence of our own culture. We usually know what we value as a group, whether this is independence, fairness, group companionship or, say, professionalism. We know what we believe in. These beliefs are closely related to our values. At work we may believe in fair play, promotion on merit, equality of contribution from colleagues and management alike, rewards when they are earned. These 'value rules' are best observed when they are infringed. Favouritism, unequal workloads, no recognition where it is due, all infringe the values of fairness, justice and equity. The values of different groups within the same organisation cannot be construed as being commonly held. Each group needs to articulate its own values and preferred value rules for operating. Effort will need to be made to select and test a set of values acceptable by both as harmonious. These values would become the guiding principles upon which future decisions and behaviors would rest:

\footnotetext{
Values are among the most stable and enduring characteristics of individuals. They are the basis upon which attitudes and personal preferences are formed. They are the basis for crucial decisions, life directions and personal tastes, much of what we are is a product of the basic values we have developed through our lives. An organisation too has a value system, usually referred to as its organisational culture. Research has shown that employees who hold values that are congruent with their organisation's values are more productive and satisfied. Holding values that are inconsistent with company values, on the other hand, is a major source of frustration, conflict and nonproductivity (Whetton \& Cameron, 1991:57).
}

Adler (1993), suggests that values are strong influencers of beliefs attitudes and behavior. They intuitively tell a person or a group if what is being done or suggested is right or wrong. This would apply for the most important of organisational activities such as the method of developing and communicating strategy, the design of structures and relationships down to the amount of personal authority accorded to each person in the organisation. 


\section{Constructivist paradigm}

Culture is not a tangible entity. It cannot be counted as a fact, even a social fact. Culture cannot be discovered as 'a reality out there somewhere'. It is not observable, measurable and exists abstractly in the mind, rather than concretely in time and space. In other words, culture is a construct, a version of 'reality' produced by one or more individuals.

A collective construct can only be approximated but nevertheless, if it is produced by members of a group, working together, a shared understanding seems possible. An appropriate theoretical framework for designing culture-based work is the constructivist framework (Schwandt, 1994)

The constructivist way of managing would focus on those activities designed to encourage shared meaning. If 'personal reality' consists of what Senge (1992:5) calls mental models of how the world should work, then presenting or prescribing one 'authentic' reality to an individual or group of people would not be too convincing. This would apply to the company policy or manual, any documentation that represented a ready-made version of reality. Negotiating shared constructs seems a more effective way of working out desired ways of behaving and achieving the "we-ness" that makes for collective programming of the mind.

\section{Theory of the core values model}

It was this kind of constructivist thinking, together with many years of experience in diverse areas of organisational life, that led to the idea that an organisation would pull together more successfully if there was less prescribed reality from management and more negotiated reality between managers and workers. Figure 1 below, shows how each group needs to contribute to an area of shared meaning to the point that each other's values can be aligned to produce a set of shared value rules.

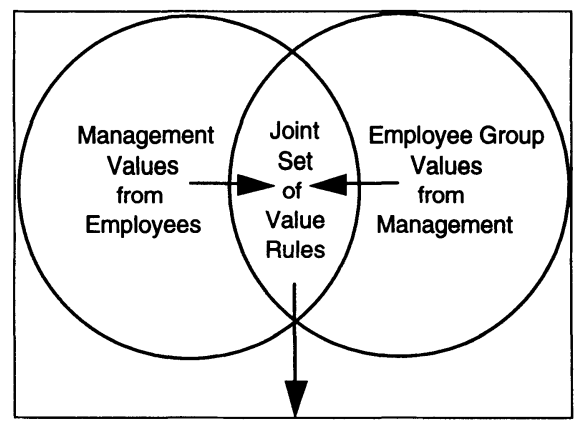

Figure 1 Internal core values (the way 'we' do things here) (reproduced from Whiteley, A. M. (1995) Managing Change: a core values approach. Macmillan Pub., Melbourne).

Negotiating the internal core values is not enough in an organisation though. Each organisation does not exist in a vacuum. Successful organisations exist to serve markets, customers and consumers as exemplified lessons in the literature from organisations such as Xerox (Kearns \& Nadler, 1993). This goes for public and private sector organisations alike. Our experience suggests that there is usually one predominant characteristic that the customers in the marketplace value from the organisation. This value can be taken as a core value and inclusion of customers' core values is an essential part of culturebuilding. The business of aligning the three sets of core values, management, employee and customer, becomes the manager's major pre-occupation in the task of culture-building. 
Although the vision making process may be started by management the contribution of each group is recognised as an integral part of the vision making process. Figure 2 shows management, employee and customer groups coming together to create shared values.

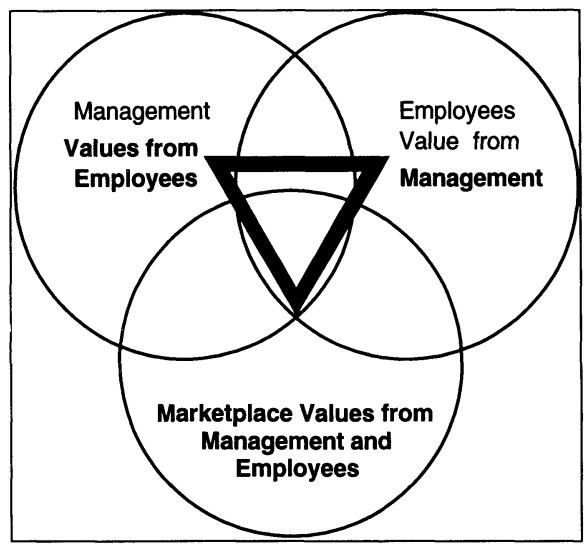

Figure 2 The three core value players (reproduced from Whiteley, A. M. (1995) Managing Change: a core values approach. Macmillan Pub., Melbourne.

The core values model is a framework for visualising the organisational process from a culturebuilding point of view. However, in this model there is a marked difference from the widely held view that vision making is the job of top management. An example of this comes out in recent research carried out in the U.K. (Aitken \& Saunders, 1995) which reports that those organisations in the study that had outstanding performance felt a large part of their success was due to the vision of top management. To them the important task was to communicate the vision effectively. This idea is shared by writers such as Kotter and Heskett (1992). When the core values model was being developed, the idea that senior managers should develop vision and pass it down the line did not seem to overcome the problem of how to include the core values of workers in such a way that they could see their values, as they produced them, reflected in the vision statement. There was something abstract, once removed, in the idea of handing values and vision down to others. This was to be tested out over the next few years using an organisational workshops method that included employee groups. Overwhelming evidence from many different work sectors suggested that workers did have values, did think they were important and did wish to see them reflected in the vision statement (Whiteley and Atkinson 1995).

For the purposes of building the model, vision was conceptualised as a mental model of the way the organisation would organise for survival and success. It represented a mindset constructed by the people who play key roles in organisational life. It has become increasingly recognised that employees are to be included in these key roles (Eden 1992). The mindset is really a philosophical statement about the 'true' nature of the marketplace, management employee relationships, and of the contribution each makes to organisational success. Early in the stages of inquiring about vision it became evident that a developed vision by itself could be of little more than symbolic significance. Stories of framed vision statements where the tellers could not remember either what they contained or how they were developed led to the notion that visions really have to work for a living. The values have to be carried through into the organisational purpose or mission.

Organisational strategies have to be tested against the shared values for compatibility (at the time of writing, so many are found not to be in tune, so putting strategic implementation at risk). Structures 
and systems have to enable the strategies and also be in tune with the shared values, as do the policies and guidelines, processes. and people management styles. What this seems to do is to increase the sense of ownership not only of the good things but also of the problems and agreed ways of developing solutions. When introducing the workshop both to managers and employees, this is explained using the figure 3 below.

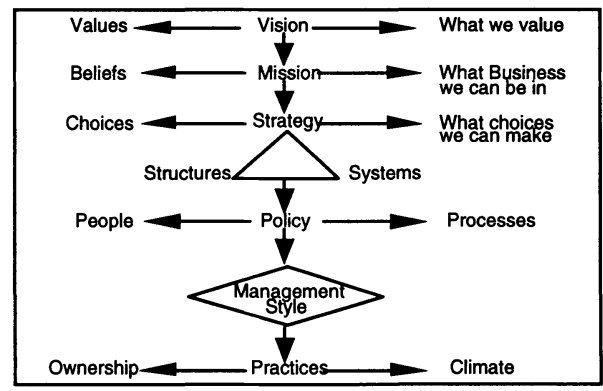

Figure 3 Vision and values carried through to daily practices (reproduced from Whiteley, A. M. (1995) Managing Change: a core values approach. Macmillan Pub., Melbourne.

\section{THE CORE VALUES METHOD}

During the development of the core values model, organisations most likely to be interested in the model and workshop method were those going through (sometimes drastic) change or faced with the prospect. Other organisations were those who needed to show improved performance and saw people as the key to this. Others were conducting strategic planning and were amenable to ideas on how to include vision making in this way.

The dominant groups were nearly always senior managers and/or human resource directors. Almost always the core values workshops were conducted with this group first, followed by the employee group. The ideal of accessing customer groups was not always achieved but in all cases work was done by the organisation to collect data on customer values and perceptions. The message that the core values method rests on the assumption that the most effective internal vision an organisation can have is one which is designed in collaboration with employees was a cornerstone of the workshops. The following narrative describes a core values initiative in a typical organisation.

There will be some preparation, perhaps over months for the sort of change which requires organisational renewal. Information about the organisation's future challenges and its state of readiness to meet them will have been communicated in such a way that the workforce can have opportunity to ask questions. During this time there will be a need to send clear signals that a new way of thinking or mindset is required. It may be a time for tough decisions. Those who can not commit to the internal model of genuine employee involvement may not feel that there is a role for them in the new organisational arrangements. Managers may have not had to rely on employee input and/or approval of decisions. They may need convincing that the realities employees construct about the organisation will be heavily influenced by management's structures, systems and methods of decision making.

Employees, especially those who are opinion leaders, whether formal or informal, will need to be prepared for the skills which are required in decision making such as planning, problem-solving, and communication. They will need to be convinced from the highest sources in the organisation that 
creating a shared vision is not a short-term crisis measure. They need to have some confidence that the energy they put into championing the new ways of thinking and operating will not be wasted when markets and economies improve. This sort of preparation will take varying amounts of time according to the existing relationships between management and employees.

When the climate is right and a reasonable amount of trust in management's and employees' intentions has been achieved then vision making sessions can be held to determine:

- an overarching vision

- internal visions for departments or groups.

As the task of leadership is to propose future direction, given that the senior management group have experience and access to environmental information this group will need to specify what it values from the workforce. Employee groups in turn will work out what they value from management. The shared values of each group will be extended to include the values of customers.

\section{THE USE OF GROUP SUPPORT SYSTEMS TECHNOLOGY}

One of the major drawbacks was conducting core values workshops in the same sort of meeting setting that previous battles have been fought and lost or won, friendships and enmities are at stake and it is the survival of the fittest in terms of being heard. These strengths of human nature work as frailties when trying to concentrate on issues rather than personalities, ensure equal opportunities for input and efficient capturing of a host of competing voices.

At the time of writing, core values workshops are still being conducted in both manual and GSS modes. The authentic work captured in the manual mode is conspicuously different from that using GSS. It is beyond the scope of this paper to go into detail, but major differences lie in the willingness of group members (manual) to clarify and make one person's idea their own. Another difference is the loss of focus in the manual mode particularly when favourite topics are aired.

Almost all management groups have used the vision making together with the first stages of strategic planning. There is still much to learn about GSS facilitation and the effect of GSS process variables on meetings (Jessup, Connolly \& Galegher, 1990; Lewis \& Whiteley, 1992; Nunamaker, 1991). This account recognises but does not deal with these in this paper as the focus is on the core values application. However one important facilitation activity, that of releasing the imaginal aspect of thinking, is necessary to vision making. So far the following imaginal releasing exercise is done manually. It is used both in vision making and strategic planning which also rests upon imagining a future.

\section{Creating future scenarios}

A simple method of releasing the imaginal (and the emotional is usually very prominent here) is to ask the visioning group members to close their eyes and imagine the organisation as it will be in five/ten years time. The scene they are imagining is bright and light. There is an air of prosperity. There is an aura of success. What sort of buildings do participants see? What sort physical layouts are in the workshops or other work areas? What can you tell about the human arrangements around the place? Who are the bosses and how can you tell? Are there any signs of the customer? Are there any symbols of how well the organisation is succeeding? How are the employees communicating? What sort of jokes and stories are being told? What values are evident in the scene you have just described?

Now the group members are asked to imagine a very different scenario. The brightness has faded away. A dullness has taken its place. There is an aura of "getting through the day as best as one can". They are asked things like these. What do the buildings look like here? How are things laid out? How 
are people relating to each other? How are managers and employees achieving goals together? How are the successes and failures communicated? What sort of stories are being told? What do you think the people here value?

Very often here one can see vision in the making. Even those participants who are metaphorically wedded to spread sheets begin the process of surfacing the inner workings of organisational life and in particular those aspects they value, feel are the right things to be doing. Although group members are invited to contribute tangible as well as intangible aspects there are always many more behavioral than substantive responses. It is not difficult to see that beliefs in the value rules governing the way people should behave are uppermost in the minds of people who are visualising themselves in a future at work.

\section{GROUP SUPPORT SYSTEMS PROCEDURES}

Following the core values method, the outcome of the first GSS step is a set of values generated by participants. Private comment enables each person to peruse the work of the group adding comments of support, agreement, disagreement, expansion to any of the contributions. Discussion and evaluation results in the adoption of one overarching or core value. The key and core values represent the value rules of the organisation from this group's point of view. Often with senior management groups, strategic planning follows the vision making, often requiring several sessions. Once the strategies are chosen, they are "tested" against the values for compatibility. A script for vision making would include:

\section{'Warm Up' generate}

Experience has shown that around thirty values can be facilitated such that each person's authentic work is processed by the group. A timed 'warm up' generate, inviting the group members to contribute a continuous list allows individuals to privately brainstorm. The use of private comment allows the usual piggy back and rethinking to further stimulate thinking;

\section{Parallel interview process (PIP)}

For the next step, observing the anonymity convention, individuals select and key in their three core values. The 'warm up' list is available in hard copy and time is given for informal discussions before choices are made. Group members are basically acting as individuals here contributions coming individually and in parallel.

\section{Discuss/Organise}

This step most closely resembles a manual workshop in that the individuals are free to talk, argue, listen, clarify and expand/contract without having to write things down, thereby identifying themselves and their particular point of view.

This is the step where the need for a constructivist paradigm is most visible. It is here one sees reality in the making. The combination of private comment and group endorsement of inputs offers more chance of commitment to the group process rather than a particular point of view.

\section{Evaluate}

The rate tool is often used so that the congruence or otherwise of individual thinking on values rated as important can surface. If there is too much dispersion then clearly more work would need to be done to see why this is so.

Because it is not possible to conduct GSS and manual sessions for this particular activity, it has not been possible to directly compare their relative effectiveness. More research will be conducted in this 
area so that a more critical view can be taken. Areas might include identifying ways of bringing more qualitative data into the GSS meetings to save time. An area that may not have been fully exploited is that of forward planning so that values can be incorporated into human resource systems and processes. This work is in its developmental stages.

\section{6}

\section{THE CONFERENCE VISION WORKSHOP}

This paper describes the way in which the core values model has been used together with GSS technology to build culture through a set of workshop activities in a number of organisations. Normally, a conference would not be an ideal environment for a demonstration because, although a conference has a unifying theme, it is not often an actionable one. However, the 1996 conference The International Office of the Future:Design Options and Solution Strategies leads up to the 1997 founding of an entity which, if we were giving it an organisational name, we could call "Global Inc." For all intents and purposes the conference workshop demonstrates a setting where the process of developing a vision and shared sense of purpose is begun.

The GSS workshop described earlier in the paper will be simulated at the 1996 conference. There are two purposes here. The first is to provide a setting for participants to think about the international office of the future concept in the company of their fellows. The second is to produce a tentative vision using the workshop mode. Members of the Organising Committee, Program Committee and Participants will represent three key stakeholding groups.

\section{$7 \quad$ CONCLUSION}

Since the late 1990's those working in the Information Technology field have recognised the qualitative aspects of meetings for which provision needs to be made.

Today's organisations face a future of increasing turbulence and international competitiveness. Rapid adaptation to change is paramount. managers spend over half of their time in meetings addressing these and other important issues. Ironically, while we have provided considerable computer-based support for individuals and the organisation as a whole, we have historically provided virtually no such support for meetings. The situation is now beginning to change...

Vogel, D. R., Nunamaker, J. F. J., Martz, W. J. J., Grohowski, R., \& McGoff, C. (1989) "Electronic

Meeting Experience at IBM", Journal of Management Information Systems, 6 (3), 26.

For example, there are a range of activities where groups come together with the need to create shared understanding. Culture building is such an activity, dealing with the most fundamental of aspects of organisational life, values. A method for developing shared values in the form of vision statements was developed over several years, using manual rather than technical facilitation. For the last three years, Group Support Systems technology has been used for this purpose with effective results. There is a need for further work both in formalising responses to the technology and using the values results for strategic and organisational planning.

\section{POSTSCRIPT - CONFERENCE FINDINGS}

The task was to use the conference attendees to begin the process of creating a shared vision for the last event in the International Office of the Future (IOF) trilogy for which "Global Inc." was the metaphor. If Global Inc. was to "walk the talk" in terms of matching the values of community and global with 
Table $1 \quad$ Emergent Themes

Vision Statement

We see Global Inc. holding a global "round the clock conference" to enable knowledge exchange and shared experiences between individuals and groups interested in the international office of the future while meeting participant expectations with minimum risk, minimum complexity, and within the constraints of available resources

Emergent Themes

1. Open participation: open sharing of information with global collaboration

To conduct an open, information-sharing experience...intended for a wide diversity of participants and topics.

2. People centered with technology as an enabling factor, not a controlling factor

The conference should be people-centered, with technology as an enabling factor and NOT a controlling factor.

3. Cooperative rather than competitive, synergistic where differences are valued

The spirit should be cooperative rather than competitive, with a synergistic approach where everyone's contribution is valued and recognized from a team perspective.

4. Multi-organizational structure adapted to different cultures

In our case, we will have an opportunity to set up a multi-organization

structure adapted to different cultures.

5. High quality

Quality sessions that incite discussions and new research ideas.

6. Springboard for future ongoing research

The conference should be a springboard for future ongoing research.

7. Helping others to know more

Be prepared to help others to know more - mentoring, assisting,

tutoring, etc.

8. Group focus

dynamics of group relationships (within groups participating)

building of group memory and studying of its dynamics.

9. Outcomes (social, conference methodology, leadership)

as a value the research should not only look at the task/production

outcomes but also at the relationship/social outcomes including "would we

want to do this again?"

10. Innovation versus traditional

The conference must be a trail-blazer in terms of multi-site conferences.

The conference must also be a trail-blazer in terms of speaker audience interaction. 
conference organisation, content and format, then the activity of constructing shared meaning was essential. The vision workshop was part of a design that included focused sessions. The output became the supporting data for the Design teams, whose brief was to advise on key conference aspects. The vision workshop was 'structured in sixes', with three pairs taking the role of the three stakeholding groups program committee, organising committee and research opportunists. The pairs convened to share their perspectives and combine them into a vision statement or a statement of values. Groups were invited to input the results electronically. One of the major uses of the vision data was to test the vision statement of the three pairs of conference coordinators, program chairs, organising chairs and research opportunist chairs for fit with those of the other groups. The fit was found to be a good one in terms of the sense of the other contributions. In addition a number of themes emerged (see Table 1 above).

The themes above were representative of the values to be preserved at the 1997 conference. As the participants said, "this really is the start of the 1997 conference". True to the values of participation and sharing, the data produced at the conference will provide the starting point for the wide dissemination of ideas, views and values that will help the conference be "a conference with a culture".

\section{REFERENCES}

Adler, N. J. (1993) “Do Cultures Vary?" In T. D. Weinshall (Ed.), Societal Culture and Management, New York: de Gruyter.

Aitken, A., \& Saunders, I. (1995) "Vision only works if Communicated", People Management (December), 28-29.

Barnouw, V. (1985) Culture and Personality. (4th ed.) New York: Dorsey Press.

Eden, C. (1992) Strategy Development and Implementation. Paper presented at the 25th Hawaii International Conference on Systems Sciences, California.

Hofstede, G. (1984) Culture's Consequences: International differences in work-related values. Beverly Hills: Sage Publ.

Hofstede, G. (1989) "The Cultural Relativity of Organizational Practices and Theories". In J.N. Sheth \& G. S. Eshghi (Eds.), Global Human Resources Perspectives, (pp. 3-19). Cincinnati: SouthWestern Pub. Co.

Jessup, L., Connolly, T., \& Galegher, J. (1990) "The Effects of Anonymity on GDSS Group Process with an Idea-Generating Task", MIS Quarterly, 14 (3), 313-321.

Kearns, D. T., \& Nadler, D. A. (1993) Prophets in the Dark: How Xerox Reinvented Itself and Beat Back the Japanese. New York: Harper Collins.

Kotter, J. P., \& Heskett, J. L. (1992) Corporate Culture and Performance. New York: The Free Press.

Kroeber, A. L., \& Kluckholn, C. (1952) "Culture: A Critical Review of Concepts and Definitions", Peabody Museum Papers, 47 (1 (Cambridge, Mass.: Harvard University)), 181.

Lewis, L. F., \& Whiteley, A. (1992) Initial Perceptions of Professional Facilitators Regarding GDSS Impacts: A study using the Grounded-Theory approach. Paper presented at the Proceedings of the 25th Hawaii International Conference on Systems Sciences.

Nunamaker, J. J., and Vogel D. (1991) "Facilitation Issues", Proceedings of the 24th Hawaii International Conference on Systems Sciences, 4 (24).

Pugh, D. S. (1993) "Organizational Context and Structure in Various Cultures". In T. D. Weinshall (Ed.), Societal Culture and Management., (pp. 425-435), Berlin: Walter de Grutyer.

Schein, E. (1985) Organisational Culture and Leadership. San Francisco: Jossey-Bass. 
Schwandt, T. A. (1994) "Constructivist, Interpretivist Approaches to Human Inquiry”. In N. K. Denzin \& Y. S. Lincoln (Eds.), Handbook of Qualitative Research, (pp. 118 - 137). New York: Sage.

Weinshall, T. D. (Ed.) (1993) Societal Culture and Management. Berlin: Walter de Grutyer.

Whetton, D. A., \& Cameron, K. S. (1991) Developing Management Skills. (2nd ed.). New York: Harper Collins.

Whiteley, A. M., \& Aitkinson, D. (1995) I.T. Tools Help the Management of Change. Paper presented at the TIMS, Singapore.

\section{BIOGRAPHY}

Associate Professor Alma Whiteley is MBA Director at the Graduate School of Business, Curtin University of Technology. Alma has a PhD from the University of Newcastle-Upon-Tyne (UK). Alma's teaching areas include International Business Competitiveness, Critical Thinking and Human Resource Strategy. Alma consults to industry (public and private sector companies) in strategic planning and in the management of change. Group Support Systems has become a central support for this work. 